\title{
Comprehension of Risk Factors of Malaria during Pregnancy among Pregnant Women Attending Antenatal Care in Malawi
}

\author{
Vivian Mpanga1, Alfred Maluwa ${ }^{2}$, Ursula Kafulafula ${ }^{3}$, Mercy Pindani' ${ }^{2}$, Kaye Bultemeier ${ }^{4}$ \\ ${ }^{1}$ Malawi College of Health Sciences, Blantyre Campus, Blantyre, Malawi \\ ${ }^{2}$ University of Malawi, Kamuzu College of Nursing, Lilongwe Campus, Lilongwe, Malawi \\ ${ }^{3}$ University of Malawi, Kamuzu College of Nursing, Blantyre Campus, Blantyre, Malawi \\ ${ }^{4}$ Georgetown University, Washington DC, USA \\ Email: aomaluwa@kcn.unima.mw
}

Received 1 October 2014; revised 3 November 2014; accepted 19 November 2014

Academic Editor: Malgorzata Nagorska, Faculty of Medicine, University of Rzeszow, Poland

Copyright (C) 2014 by authors and Scientific Research Publishing Inc.

This work is licensed under the Creative Commons Attribution International License (CC BY).

http://creativecommons.org/licenses/by/4.0/

(c) (i) Open Access

\section{Abstract}

A study was conducted to determine the comprehension of pregnant women on malaria risk factors during pregnancy. Comprehension of Malaria risks is important to ensure compliance to prevention methods and treatment by the pregnant women and hence optimizes the pregnancy outcomes. The study was conducted in 2012 at three health facilities, Queen Elizabeth Central Hospital, Ndirande health Centre and St. Joseph Mission Hospital in Malawi. The study design was descriptive and utilized quantitative data collection and analysis methods on a random sample of 316 antenatal mothers. The study targeted antenatal mothers who were aged between 15 and 49 years, in the gestation period of 28 to 36 weeks and able to converse in English or vernacular language. A structured questionnaire was used to collect data which were analyzed using SPSS version 16.0. Most of the participants $(79.4 \%, n=251)$ knew the risk factors of malaria during pregnancy but very few $(18.4 \%, n=58)$ knew about intermittent prevention treatment despite taking SP as prescribed. The motivation factors for taking SP were husband support and the desire to protect their babies and themselves from Malaria. Although the comprehension of the intermittent prevention treatment among the women was low, the women were motivated to adhere to the treatment when instructed by the healthcare workers due to the desire for good health for themselves and their unborn babies. Husbands were the most significant other that motivated the pregnant women to adhere to treatment. Results show that there is a need for healthcare workers to facilitate comprehension of intermittent prevention treatment among pregnant mothers.

\footnotetext{
${ }^{*}$ Corresponding author.
} 


\section{Keywords}

\section{Direct Observation Treatment (DoT), Intermittent Prevention Treatment (IPT), Malaria Risk in Pregnancy, Adherence to Anti-Malaria Chemoprophylaxis, Sulphadoxine-Pyrimethamine (SP), Malaria Parasite}

\section{Introduction}

Malaria is the world's most important tropical disease which kills more people than any other communicable disease [1]. In the sub Saharan Africa, malaria affects an estimated 24 million pregnant women and hence the region records the greatest severity of malaria accounting for $90 \%$ of all the deaths [1] [2]. Malaria in the sub Saharan African region is caused by Plasmodium falciparum, which is the most dangerous parasite. The $P$. faciparum is confined to tropical or sub tropical regions, because its development is greatly retarded when the temperature falls below $20^{\circ} \mathrm{C}$. In the tropics malaria is more common in pregnant women than in any other adult group because of the hormonal and immunological changes that take place in the pregnant women's body [3]. The presence of $P$. falciparum in pregnant women may lead to negative birth outcomes. Some of the established negative impacts of malaria on pregnancy outcomes include a high incidence of miscarriages and a high number of deliveries of low birth weight babies [4].

Placental malaria is common among pregnant women and is fatal to both the mother and her fetus. Maternal malaria causes placental insufficiency leading to low birth weight [4]. In addition, pregnant women who have severe $P$. falciparum infection are at risk of developing severe anemia [5]. It is therefore estimated that malaria is responsible for $19 \%$ of low birth weight in infants that are born in malaria endemic areas [6].

In an effort to control the malaria, the World Health Organization (WHO) developed a strategic framework that guides countries to formulate their own policies [7]. The guide recommends the use of Intermittent Prevention Treatment (IPT) with sulfadoxine-pyrimethamine (SP), use of insecticides treated bed nets (ITNs) and good case management of malaria. The IPT has shown to be one of the potential approaches to reduce malaria complications during pregnancy [5]. Malawi adopted the WHO IPT policy and hence provides at least two doses of SP to pregnant women during 2nd and 3rd trimesters. The SP is given to the pregnant women twice during her pregnancy in a space of at least a month beginning not later than 36 weeks of gestation under direct observation treatment (DOT). The coverage of pregnant women receiving at least two doses of IPT has reached $60 \%$ and over $80 \%$ of women in Malawi have taken IPT at least once during their pregnancy [8].

Despite the malaria in pregnancy control efforts, the majority of pregnant women have difficulties to explain risks of malaria in pregnancy suggesting that there may be a problem with the women's comprehension of malaria risks in pregnancy and compliance to anti-malaria guidelines [9]. Understanding of malaria risks or effects and its prevention can greatly assist in reduction of maternal and infant mortality rates. Studies have shown high usage of ITP when communities understand malaria transmission, recognize the signs and symptoms, cause, treatment and preventive measures [10]. However, in Malawi literature on comprehension of pregnant women on malaria risks and its prevention is scanty. This study was therefore conducted to investigate the comprehension of the risks of malaria in pregnancy among pregnant women attending antenatal care (ANC), so that appropriate interventions to protect the pregnant mothers and their infants from malaria are developed and implemented.

\section{Objectives}

The objectives of the study were to:

1) Determine the comprehension of pregnant women on risks and effects of malaria in pregnancy;

2) Determine the pregnant women's adherence to anti-malaria prophylaxis;

3) Identify factors that influence or motivate pregnant women to take SP.

Based on these objectives, the study was therefore conducted to answer the following research questions:

1) Are women in Malawi aware of the risks and effects of malaria in pregnancy?

2) Do pregnant women in Malawi adhere to anti-malaria prophylaxis?

3) What factors influence or motivate pregnant women to adhere to SP prophylaxis? 


\section{Methods}

\subsection{Design}

The study design was descriptive cross sectional and utilized quantitative data collection and analysis methods to assess antenatal mother's knowledge on risks of malaria in pregnancy and their adherence to anti-malaria chemoprophylaxis.

\subsection{Setting}

The study was conducted at three antenatal clinics. The first was Queen Elizabeth Central Hospital (QECH), which is a tertiary referral health facility situated in Blantyre city but serving the whole southern region. The second facility was Ndirande Health Centre, a primary health care facility within the city of Blantyre. At the time of the study the city had a population of 661,256 of which 336,234 were males and 325,022 were females [9]. A third clinic was St. Joseph Mission Hospital in Chiradzulu district. This facility represented a rural setting and its catchment area had 42,109 people out of which 19,250 were males and 22,750 were females [9].

\subsection{Sample}

A random sample of 316 women was drawn from all pregnant women at the three antenatal clinics that met the inclusion criteria. At QECH and St. Joseph Mission Hospital, 100 pregnant women were recruited from each site while 116 women were recruited from Ndirande health center. Sample size was calculated using the proportion of women that attended ANC at each site out of all the women in the child bearing age in the catchment area [11]. The allowable error was set at 0.05 and a $95 \%$ confidence interval was used.

\subsection{Inclusion and Exclusion Criteria}

To be included in the study, the pregnant women had to be aged between 15 and 49 years, in the gestation period of 28 to 36 weeks and able to converse in English or vernacular language. The study excluded all antenatal women whose gestation period was below 28 and above 36 weeks, or were aged below 15 or over 49 years, were unable to communicate in English or vernacular language. In addition, HIV positive women who were on daily cotrimoxazole prophylaxis were excluded from the study.

\subsection{Data Collection}

Data were collected over a period of 5 weeks from July to early September in 2011. A structured questionnaire was administered orally by the senior author who is a State Registered Nurse Midwife during an in-depth face to face interview with the participants. At each facility, the researcher introduced herself and explained the study and its purpose to the women during their ANC education. An invitation was extended to those willing to participate in the study to meet the researcher at an identified place and agreed time. Health passport books were reviewed to identify antenatal women who met the study's inclusion criteria. Small white stickers were placed on the passbooks to identify eligible participants. The eligible participants were allocated numbers. Interviews were conducted with randomly selected participants using their allocated numbers. Interview questions centered on assessment of the mothers' knowledge of malaria, the risks of malaria on mother and baby and prevention strategies. Other questions examined motivation factors for antenatal women to take SP and to comply with anti-malaria treatment. Health passport books were also used to verify administration of SP.

\subsection{Data Analysis}

Data were analyzed using SPSS version 16.0. Descriptive statistics in the form of frequencies and percentages were computed for the categorical variables and frequencies, percentages and means were computed for the non categorical variables. The following variables were measured during the study; Mothers demographic variables (age, marital status, number of children and education levels), comprehension on risks of malaria in pregnancy, prevention strategies and personal and social factors that affected adherence to prophylaxis within the health facility. 


\subsection{Ethical Consideration}

The study was approved by the College of Medicine Research and Ethics Committee (COMEC) which is the internal ethical review board for Kamuzu College of Nursing. Permission to conduct the study at the three facilities was obtained from the Directors of the facilities. The interviews were conducted in a quiet room that ensured privacy and freedom from disturbances. The intention of the study and further information regarding the study were also explained to the participants privately. The participants were told that participation was voluntary hence they were free to opt out of the study at any point if they wished to do so and such a decision would not affect their care at the facility. They were also assured of anonymity at all times during data collection, analysis and dissemination. Interviews were conducted after each participant gave an informed consent.

\section{Results}

\subsection{Demographic Characteristics of Participants}

The total number of participants was 316, out of which 100 each were drawn from QECH and St. Joseph Mission Hospital. The remaining 116 were drawn from Ndirande health center. Overall, the majority $(93 \%, \mathrm{n}=294)$ of the participants were married. The participants' ages ranged from 15 to 49 years with a mean age of 26.5 years at QECH, 24.8 at Ndirande and 24.5 years at St. Joseph. The percentage of participants in each age group within a health facility is shown in Table 1 . Most of the participants $(89 \%, \mathrm{n}=89$ at QECH, $78 \%, \mathrm{n}=90$ at Ndirande and $77 \%, \mathrm{n}=77$ at St. Joseph Mission Hospital) were aged between 20 and 35 years and there were few participants in the above 36 years old age category (Table 1 ).

There were $98.3 \%, \mathrm{n}=98$ of the participants that resided in peri-urban setting (Ndirande), $94 \%, \mathrm{n}=94$ in rural (St. Joseph) and 76\%, $\mathrm{n}=76$ in urban (QECH) setting. Regarding levels of education, most of the participants at St. Joseph Mission Hospital and Ndirande did not attain any secondary school education hence their educational level was low. At St. Joseph, $49 \%, \mathrm{n}=49$ of the participants attempted primary school, while at Ndirande, $74 \%, \mathrm{n}=86$ had not attained any secondary school education. However, at QECH, $52 \%, \mathrm{n}=52$ of the participants had completed secondary school. In view of the low education levels, most of participants were housewives with 93\%, $\mathrm{n}=93$ each at QECH and St. Joseph, and 89.7\%, $\mathrm{n}=104$ at Ndirande. The majority of the participants (over 70\%, $\mathrm{n}=226$ at each facility) reported having knowledge of the differences between pregnant and non pregnant women.

\subsection{Knowledge of the Effects of Malaria on Pregnant Woman}

Majority of women $(\mathrm{QECH}=86 \%, \mathrm{n}=86$, Ndirande $=75.9 \%, \mathrm{n}=88$ and St. Joseph $=75 \%, \mathrm{n}=75) \mathrm{knew}$ that malaria causes serious effects to a pregnant woman. The participants were able to mention more than one effect of malaria on a pregnant woman. Percentages of participants that mentioned a combination of effects of malaria during pregnancy are shown in Table 2.

Table 1. The percentages of participants within each age group at each health facility.

\begin{tabular}{|c|c|c|c|c|c|c|c|}
\hline \multirow[b]{2}{*}{ Facility } & \multicolumn{7}{|c|}{ Age Group (Years) } \\
\hline & $\begin{array}{l}\leq 19 \\
(\%)\end{array}$ & $\begin{array}{c}20-23 \\
(\%)\end{array}$ & $\begin{array}{c}24-27 \\
(\%)\end{array}$ & & $\begin{array}{l}-31 \\
0)\end{array}$ & $\begin{array}{c}32-35 \\
(\%)\end{array}$ & $\begin{array}{l}\geq 36 \\
(\%)\end{array}$ \\
\hline Queen Elizabeth Central Hospital (\%) & 7 & 20 & 31 & & 1 & 17 & 4 \\
\hline Ndirande Health Center (\%) & 16 & 33 & 22 & & 2 & 11 & 6 \\
\hline \multirow[t]{2}{*}{ St. Joseph Mission Hospital (\%) } & 21 & 24 & 25 & & 7 & 11 & 2 \\
\hline & \multicolumn{7}{|c|}{ Education Levels } \\
\hline Facility & \multicolumn{2}{|c|}{ Did not attend school } & Primary s & \multicolumn{3}{|c|}{ Secondary school } & College \\
\hline Queen Elizabeth Central Hospital (\%) & \multicolumn{2}{|c|}{1} & 30 & \multicolumn{3}{|c|}{57} & 12 \\
\hline Ndirande Health Center (\%) & \multicolumn{2}{|c|}{6} & 48 & \multicolumn{3}{|c|}{43} & 3 \\
\hline St. Joseph Mission Hospital (\%) & \multicolumn{2}{|c|}{4} & 50 & \multicolumn{3}{|r|}{45} & 1 \\
\hline
\end{tabular}


Table 2. Percentages of participants that mentioned a combination of effects of malaria during pregnancy.

\begin{tabular}{cccc}
\hline Variables & QECH (\%) & Ndirande (\%) & St. Joseph (\%) \\
\hline Did not know & 12 & 12.1 & 12 \\
Anemia and death & 13 & 6.9 & 1 \\
Transmits malaria to baby & 2 & 0.9 & 34 \\
Maternal death & 27 & 31 & 10 \\
Abortion & 8 & 11.2 & 0 \\
Body weakness and loss of weight & 1 & 0 & 5 \\
Anemia death and body weakness & 2 & 3.4 & 1 \\
Maternal death and body weakness & 2 & 3.4 & 11 \\
Anaemia & 8 & 6 & 1 \\
Maternal death and abortion & 6 & 4.3 & 2 \\
Body weakness & 10 & 8.6 & 2 \\
Anemia and abortion & 3 & 0.9 & 2 \\
Body weakness and prematurity & 1 & 0.9 & 0 \\
Anemia and body weakness & 2 & 0.9 & 4 \\
Body weakness and abortion & 1 & 0.9 & 3 \\
Death and premature delivery & 2 & 6 & 2.6 \\
Premature delivery & 0 & 2 & 2 \\
\hline
\end{tabular}

\subsection{Knowledge of Risks of Malaria to the Unborn Baby}

The knowledge of the effects of malaria to the unborn baby was high among the participants. About $90 \% \mathrm{n}=90$ of the participants knew the risks at QECH, 95\%, $\mathrm{n}=110$ at Ndirande and $89 \%, \mathrm{n}=89$ at St. Joseph. The known risks of malaria to unborn baby included; spontaneous abortion, prematurity, stillbirth, low birth weight and transmission of HIV to the unborn baby if the mother is HIV positive.

\subsection{Knowledge of Intermittent Prevention Treatment Program}

Most of the participants in the three facilities did not know the components of the IPT program (IPTp). The highest proportion of only $20 \%, \mathrm{n}=20$ was recorded at $\mathrm{QECH}$, seconded by $9.5 \%, \mathrm{n}=11$ from Ndirande and the least was $2 \%, \mathrm{n}=2$ from St. Joseph. The participants indicated that they were not formely told by the health personnel regarding IPTp. QECH reported 16\%, $\mathrm{n}=16$ Ndirande, $24.1 \%, \mathrm{n}=28$ and St. Joseph $43 \%, \mathrm{n}=43$ women who had never heard about the IPTp.

\subsection{Knowledge of Malaria Prevention Strategies}

The percentages of women who knew malaria prevention strategies are shown in Table 3. Most of the participants identified use of mosquito nets as the common prevention strategy of malaria. Burning of coil or herbs were the least known methods among the participants (Table 3).

\subsection{Source of Malaria Prevention Information}

Most of the women reported that they gained information regarding malaria prevention from the midwife (66\%, $\mathrm{n}=66$ from QECH, 65.5\%, $\mathrm{n}=76$ from Ndirande and 76\%, $\mathrm{n}=76$ from St. Joseph). There was also a small proportion of the participants $(4 \%, \mathrm{n}=4$ from $\mathrm{QECH}, 7.8 \%, \mathrm{n}=9$ from Ndirande and $10 \%, \mathrm{n}=10$ from St. Joseph) who received the information from the health surveillance Assistants. A part from the health workers the other sources of information for the participants are shown in Table 4. The radio was the most common source of information, followed by television, newspaper and village health counselor. The least important sources of information for the participants were church and school. 
Table 3. Percentages of women who knew the malaria prevention method $(n=316)$.

\begin{tabular}{cccc}
\hline Method & QECH $(\%)(\mathrm{n}=100)$ & Ndirande $(\%)(\mathrm{n}=116)$ & St. Joseph $(\%)(\mathrm{n}=100)$ \\
\hline Intermittent preventive treatment & 28 & 15.5 & 12 \\
Insecticide treated net & 89 & 92.2 & 91 \\
Spraying insecticides & 23 & 12.9 & 35 \\
Clearing and cutting grass short & 32 & 38.8 & 18 \\
Draining stagnant water & 54 & 19 & 3 \\
Burning herbs and coil & 1 & 0 & 35 \\
\hline
\end{tabular}

Table 4. Percentages of participants that mentioned other sources of IPT information other than health workers $(n=316)$.

\begin{tabular}{cccc}
\hline Source & QECH $(\%)(\mathrm{n}=100)$ & Ndirande $(\%)(\mathrm{n}=116)$ & St. Joseph $(\%),(\mathrm{n}=100)$ \\
\hline Radio & 81 & 81 & 55 \\
Television & 35 & 23.3 & 9 \\
Newspaper & 13 & 23.3 & 2 \\
Church & 3 & 1.7 & 1 \\
Friends & 7 & 3.4 & 46 \\
Village health counselor & 16 & 23.3 & 2 \\
\hline
\end{tabular}

\subsection{Adherence to Chemoprophylaxis}

The proportion of women who had taken SP during the previous pregnancies was high in all the facilities. At QECH, 68\%, $\mathrm{n}=68$ had taken SP during the previous pregnancy while at Ndirande the percentage was $68.1 \%, \mathrm{n}$ $=79$ and at St. Joseph the percentage was $74 \%, n=74$. However, there were $4 \%, n=4$ of the participants that never took any SP during pregnancy at QECH, $1.7 \%, \mathrm{n}=2$ at Ndirande and $2 \%, \mathrm{n}=2$ at St. Joseph. During the current pregnancy, the proportions of the participants that took SP were very high at each facility $(99 \%, \mathrm{n}=99$ at QECH and 100\% each at Ndirande and St. Joseph). Almost all participants $(96.6 \%, \mathrm{n}=115)$ at Ndirande and $80 \%, \mathrm{n}=80$ at St. Joseph adhered to the DOT, i.e., took the SP immediately at the facility. However, at QECH only $21 \%, \mathrm{n}=21$ adhered to DOT. About $32 \% \mathrm{n}=32$ of the participants at QECH indicated that they did not adhere to DOT because they were not instructed by the health workers to take the medication immediately.

\subsection{Period of SP Administration}

The administration of SP doses varied with facility. The first dose of SP was primarily given between 21 to 23 weeks of gestation at QECH while at Ndirande it was given between 24 to 28 weeks and at St. Joseph it was given between 16 to 20 weeks. The second dose was given most frequently between 29 to 32 weeks at QECH while at Ndirande and St. Joseph the second dose was given between 25 and 28 weeks of gestation.

\subsection{Personal and Social Motivation}

Results show that there were motivating factors that facilitated the participants' decisions on taking SP. The motivating factors included opinions of significant others such as the husband, friends and relatives. The husbands were the most important significant other that motivated the pregnant women to take SP. The percentages of the participants that were assisted by their husbands to take SP were as follows; 68\% $(\mathrm{n}=68)$ at QECH, $35.3(\mathrm{n}=$ 42 ) at Ndirande and $43 \%, n=43$ at St. Joseph.

\section{Discussion}

In this study teenage pregnant mothers comprised $14.7 \%$ of all the participants from the three health facilities. According to the 2010 Malawi Demographic and Health Survey, $65 \%$ of women in Malawi become mothers by the age of 20 [9]. Teenage pregnant mothers are associated with more pregnancy related complications and ma- 
laria in pregnancy is more prevalent in the younger than older aged mothers [12]. A study by Rogerson [13] demonstrated that malaria parasites were more common in teenage primigavidas as opposed to those that were older. The results that the majority of the participants in this study were aged between 20 and 27 agree with those reported in Nigeria where the majority of the pregnant women who attended ANC were in the same age category [14].

Most of the participants (about 90\% at St. Joseph and over 90\% at QECH and Ndirande) were married. These results are desirable as the husbands were reported to motivate their wives to adhere to IPT. These results are supported by the information motivation behavioral (IMB) skills model which suggests that for adherence to be effective there is a need for social motivation by support systems such as significant others including the spouses [15]. These results further agree with those reported by NSO [9] which stated that in Malawian culture, husbands are influential as they make most of the decisions in the house and the women are likely to follow what their husbands tell them.

In this study most of the participants that had at least attempted secondary education were from the city setting (QECH). These results agree with the results of the 2010 Malawi Demographic Health Survey which reported that women in urban areas were more educated than those in the rural and peri-urban areas [9]. A study in Nigeria demonstrated that participants that were highly educated had significantly better knowledge of antimalarial chemoprophylaxis and higher level of usage than those that had low education [16]. Additionally the study showed that positive attitudes towards malaria chemoprophylaxis were very high among the educated. In this study, the overall percentage of women who did not comply with the DOT method was very low at QECH because only few women took SP immediately at the facility's antenatal clinic. In addition, health workers at QECH did not verify whether the women who confirmed taking SP at home had complied. The implication of these results is that the facilities did not comply with the WHO recommendation on malaria in pregnancy control as there is a possibility for non compliance by the women.

The majority of women in this study knew that malaria in pregnancy presents different effects and risks on pregnant women. The results therefore show that the women were more likely to adhere to IPT thus avoiding malaria in pregnancy related complications. The study has further indicated that the majority of the participants could not identify malaria as a significant contributor to anemia. Women at QECH indicated a higher percentage of understanding that anemia was caused by malaria than those in Ndirande and St. Joseph Mission Hospital. These results suggest that the women in the study especially those from the rural facility (St. Joseph) had little information on malaria as one of the causes of anemia. The clinical implication is that women with potential risk of anemia would not be able to detect it if they had malaria thus leading to complications. There is therefore a need for managers of health facilities to intensify the provision of information on risks and prevention of malaria in pregnancy. Such efforts would contribute towards the attainment of MDGs 4 and 5.

The health workers especially the midwives were the most important source of information for the participants. These results are desirable because the health workers provide accurate information to clients. The radio was the other major source of information for the participants in this study a part from the midwives. According to the 2010 Malawi Demographic and Health Survey, 70.3\% households from urban areas own radios and from the rural areas $49.8 \%$ households own radios [9]. Moreover there are several radio stations currently running in Malawi. About 57\% of women in Malawi listen to the radio at least once a week hence intensifying health messages about malaria through the radio on daily basis would improve women comprehension of IPT [9]. A study in Nigeria reported that the media sources were frequently used as compared to other sources like school, friends, church, and relatives [17]. Although the media shows a higher percentage of use it is very important to point out that use of the newspapers in Malawi is limited. Therefore increasing coverage of the radio rather than print media about the risks of malaria would improve comprehension and adherence to SP.

Few women from all the sites were aware that malaria can be prevented through IPT using SP. Findings imply that there was low provision of information, education, and communication regarding the IPT method of malaria prevention. Women indicated that the information known was largely acquired from their own sources as most of them were not formally told by the health personnel. Similar study in Nigeria reported that $52 \%$ of the women had heard about IPT but only $26 \%$ were able to accurately define it [17]. Making women understand reasons for taking malaria chemoprophylaxis may enhance IPT uptake and its compliance although Mbonye et al. [18] indicated that community members questioned the rationale of giving SP to pregnant women when they were not showing any signs of malaria.

Results of the study indicate use of mosquito nets as the most known strategy for malaria prevention in all the 
facilities. These results may be due to the intensive campaigns conducted in Malawi in a three pronged approach to ITN distribution which included; routine free distribution of nets through antenatal clinics and Expanded Program of Immunization clinics, periodic mass campaigns covering the entire population, and the traditional social marketing through private sector outlets. The same approach can be used to campaign IPT program and make it more effective.

Overall respondents' knowledge of prevention of malaria through draining stagnant water was very poor in the semi urban setting (Ndirande) and rural setting (St. Joseph) but higher in the city (at QECH). However observations have shown that in most of the rural and peri urban areas there was stagnant water around most houses. The stagnant water areas become breeding places for mosquitoes which increases malaria outbreaks [2]. Vigilant and regular Information Education Communication and community visits would improve the information women acquire, thus assisting them to prevent malaria.

Women were motivated to take SP following previous intake especially when there were no noticeable side effects and the desire to protect the unborn babies. However number of doses taken differed as women from QECH and Ndirande were given two to three doses while those from St. Joseph had received two or less doses. Results have shown that women received the first dose of SP consistent with the recommended period by WHO which is from 16 weeks in multigravidas and 20 weeks in primgravidas. However the study results show that few women at QECH received SP before 16 weeks which contravenes the WHO recommendation. The drugs may affect the growing baby during characteristics exposure to teratogenics and also during organogenesis which can cause abortion, major and minor structural defects and growth retardation [19]. Therefore it is important that $\mathrm{SP}$ administration is avoided before quickening.

The midwives were the only health care personnel that administer SP to women at QECH antenatal clinic. The giving of SP earlier than recommended time may suggest that there may be limited knowledge among midwives at QECH on the actual timing of SP IPTp. This finding concurs with results of the survey of health workers in Malawi that demonstrated that one of the reasons that SP IPTp was not provided according to guidelines was the limited knowledge as to when the SP should be provided and when to be withheld [20]. Consequently, some women from the sites did not receive the second dose of SP.

The study has shown that women who took SP were following instructions from health workers. Hence women at QECH were advised to take SP at home and not using the DOT. On the other hand women who were told to take SP immediately using the DOT from Ndirande and St. Joseph were also instructed by the health workers and took the SP before leaving the clinic. The findings therefore show that adherence to DOT was poor at QECH but good at Ndirande and St. Joseph due to the differences in the instructions issued by the health workers. Low use of DOT may compromise uptake of IPT by pregnant women. The WHO strategy to control malaria recommends use of DOT method in administration of anti-malaria prophylaxis to ensure compliance [7]. If women are given SP to take at home there is a possibility that the medication may not be taken thus negatively affecting adherence. There is therefore a need for health workers to ensure that pregnant women adhere to DOT of IPTp.

The desire for the women to protect themselves as well as their unborn babies from malaria was the highest motivation factor in all the facilities for women to take SP IPTp. These results imply that the women were making efforts to ensure their good health as well as that of their babies. Furthermore, the women provided opportunities to health care staff to render quality care. Therefore if the women had comprehended properly about IPT, its adoption and utilization among the women would be high. The study further indicated that there was a significant association between motivating factors and behavior as shown by the women during the time they were taking SP. Few women, from all the health facilities reported that they took SP because they respected medical advice. Results demonstrate that pregnant women respected authority and believed that whatever the health personnel advised them had to be followed. Therefore the women would be at risk of complications if wrong information is given to them. Patients often see a health worker as person of authority, one in possession of specific expertise and in whom the patients invest hope for assistance in recovery [21]. In a study conducted in Gambia, results show that women were entirely dependent on ANC nurses to provide them IPTp correctly as they believed health workers would never dispense unsafe drugs [21]. In this study women's lack of knowledge on SP schedule may have resulted in poor adherence as drugs were not taken at the right time.

\section{Conclusion}

The pregnant women were aware of the risks of Malaria in pregnancy in all the facilities. Hence, despite their 
lack of specific knowledge on IPTp, they still complied with the treatment because they obeyed instructions from the healthcare workers. Husbands were important significant others that also motivated the pregnant women to take SP during IPT. Results implied that the desire for good health for both the mothers and their children and influence of significant others especially husbands were motivating factors for the women to adhere to IPTp despite their lack of knowledge on the program. Compliance to DOT among the participants across the facilities was variable. At QECH most of the participants did not comply with DOT as the women were advised to take the SP at home. However, at Ndirande and St. Joseph, there was high compliance to DOT as a result of good advice from health workers. Results implied that there was an opportunity for health workers to teach the participants and thus create comprehension among the women on IPTp because the women obeyed the health worker instructions. There is therefore a need to train the health workers on IPTp, so that in turn they can create comprehension of the program among the pregnant women. There is a need to train health workers on the 2004 WHO recommendations on strategic framework for malaria prevention. In addition, there is a need to involve the husbands in the reproductive health of their wives, because the husbands are the most important significant other among the pregnant women.

\section{Implications for Practice}

- Pregnant women provide an opportunity for uptake of IPTp because they follow all the instructions given by the health workers

- The desire by the participants to ensure good health for themselves and their babies and advice of significant others especially the husbands are motivation factors for clients to participate in IPTp.

- There is a need to equip the health care providers so that they can educate pregnant mothers to comprehend the IPTp.

\section{Study Limitation}

The study was conducted in three health facilities which were located in different geographic locations and were also at different levels of the health care system in Malawi. Queen Elizabeth Central hospital is a tertiary referral facility in the city of Blantyre, while Ndirande health center is a primary facility located in a semi-urban area of the city. St. Joseph is located in a rural area and is also a private facility managed by the Christian Healthcare Association of Malawi. The differences in the geographic locations and management levels may have affected the knowledge of the health workers on IPTp.

\section{Acknowledgements}

The study was conducted as part of the senior author's Master of Science degree in Midwifery at the University of Malawi, Kamuzu College of Nursing with a scholarship from Global AIDS Interfaith Alliance (GAIA). The preparation of the manuscripts for publication was funded by the Arctic University of Norway at Tromso and the Agency for Norwegian Development Cooperation.

\section{Conflict of Interest}

None of the authors had any conflict of interest for the manuscript to be published in the Open Journal of Nursing.

\section{References}

[1] Uneke, C.J., Iyare, F.E. and Sunday-Adeoye Ajayi, J.A. (2007) An Assessment of the Impact of Placental Plasmodium Malaria and Perinatal Outcome in Nigeria. Internet Journal of Parasitic Diseases, 3.

[2] Nwagha, U.I., Nwagha, T.U. and Nyaechie, U.S. (2009) Asymptomatic Plasmodium Parasitaemia in Pregnant Nigerian Women Almost a Decade after Roll Back Malaria. Transactions of Royal Society of Tropical Medicine and Hygiene, 103, 16-20. http://dx.doi.org/10.1016/j.trstmh.2008.07.016

[3] Samak, A.C. (2004) Malaria in Pregnancy: An Overview. McGill Journal of Medicine, 8, 66-71.

[4] Warrell, D.A. and Gilles, H.M. (2002) Essential Malariology. 4th Edition, Arnold, London.

[5] Adam, I., Khamis, A. and Elbashir, M. (2005) Prevalence and Risk Factors for Plasmodium Falciparum Malaria in 
Pregnant Women of Eastern Sudan. Malaria Journal, 4, 18. http://dx.doi.org/10.1186/1475-2875-4-18

[6] Guyatt, H.L. and Snow, R.W. (2010) Impact of Malaria during Pregnancy on Low Birth Weight in Sub Saharan Africa. Clinical Microbiology, 17, 760-769.

[7] WHO (2004) A Strategic Framework for Malaria Prevention and Control during Pregnancy in the African Region. WHO Regional Office for Africa, Brazzaville.

[8] Ministry of Health (2007) Training Guide for 2007 National Guidelines for Diagnosis, Treatment and Prevention of Malaria in Malawi. National Malaria Control Program, Ministry of Health, Lilongwe.

[9] National Statistical Office (NSO) and ICF Macro (2011) Malawi Demographic and Health Survey 2010. National Statistical Office, Zomba.

[10] Hlongwana, K.W., Mabaso, M.L.H. and Kunene, S. (2009) Community Knowledge, Attitudes and Practices (KAP) on Malaria in Swaziland: A Country Earmarked for Malaria Elimination. Malaria Journal, 8.

[11] Lemeshow, S.K., Hosmer, D.W. and Klar, J. (1990) Adequacy of Sample Size in Health Studies. John Wiley \& Sons, Chichester.

[12] Bouyou-Akotet, M.K., Lonete-Collard, D.E. and Mabika, M. (2003) Prevalence of Plasmodium falciparum Infection in Pregant Women in Gabon. Malaria Journal, 2, 18.

[13] Rogerson, S.J., Chaluluka, E. and Kanjala, M. (2000) Intermittent Sulfadoxine, Pyrimethamine in Pregnancy: Effectiveness against Malaria Morbidity in Blantyre Malawi in 1999. Transactions of the Royal Society of Tropical Medicine and Hygiene, 94, 549-553. http://dx.doi.org/10.1016/S0035-9203(00)90083-X

[14] Dairo, M.D. and Owoyokun, K.E. (2010) Factors Affecting the Utilization of Antenatal Care Services in Ibadan, Nigeria. Benin Journal of Postgraduate Medicine, 21, 3.

[15] Fisher, J., Fisher, W. and Amoco, R.K. (2006) An Information Motivation, Behavioral Skills Model of Adherence to Antiretroviral Therapy. Health Psychology, 25, 462-473. http://dx.doi.org/10.1037/0278-6133.25.4.462

[16] Abasiattai, A., Etukumana, E. and Umwiyoho, A. (2009) Awareness and Practice of Malaria Prevention Strategies among Women of Uyo, South, South Nigeria. Internet Journal of Gynecology and Obstetrics, 11, 4.

[17] Akileye, S., Falade, C. and Ajayi, I. (2009) Knowledge and Utilization of Intermittent Prevention Treatment among Pregnant Women Attending Antenatal Clinics in Primary Health Care Centers in Rural Southwest Nigeria: A Cross Sectional Study. BMC Pregnancy and Childbirth, 9, 28. http://dx.doi.org/10.1186/1471-2393-9-28

[18] Mbonye, A.K., Neema, S. and Magnussen, P. (2006) Perceptions on Use of SP in Pregnancy and the Policy Implications for Malaria Control in Uganda. Health Policy, 77, 279-289.

[19] Cunningham, F.G., Hauth, J.C. and Leveno, K.J. (2005) Williams Obstetrics. 22nd Edition, McGraw-Hill, New York.

[20] MIPESA (2004) Malaria in Pregnancy in East and Southern Africa. http://jid.oxfordjournals.org

[21] Brabin, L., Stokes, E. and Dumbaya, I. (2009) Rural Gambian Women's Reliance on Health Workers to Deliver Sulphadoxine-Pyrimethamine as Recommended Intermittent Prevention Treatment for Malaria in Pregnancy. Malaria Journal, 8, 25. 
Scientific Research Publishing (SCIRP) is one of the largest Open Access journal publishers. It is currently publishing more than 200 open access, online, peer-reviewed journals covering a wide range of academic disciplines. SCIRP serves the worldwide academic communities and contributes to the progress and application of science with its publication.

Other selected journals from SCIRP are listed as below. Submit your manuscript to us via either submit@scirp.org or Online Submission Portal.
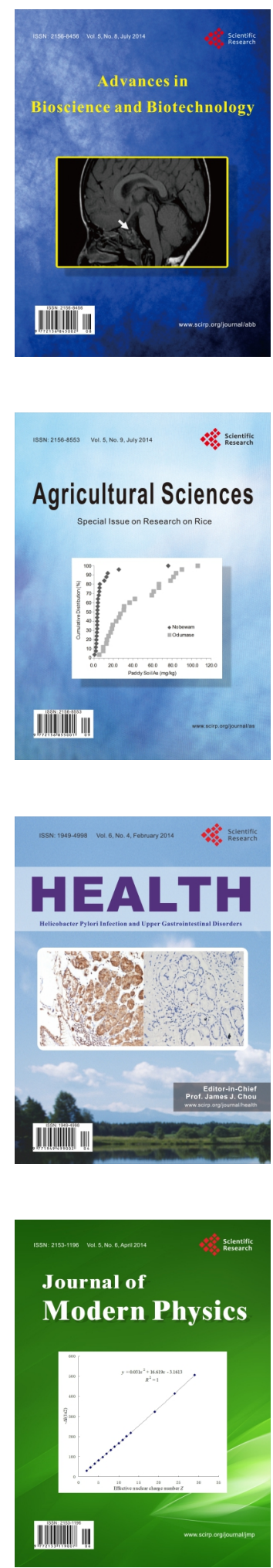
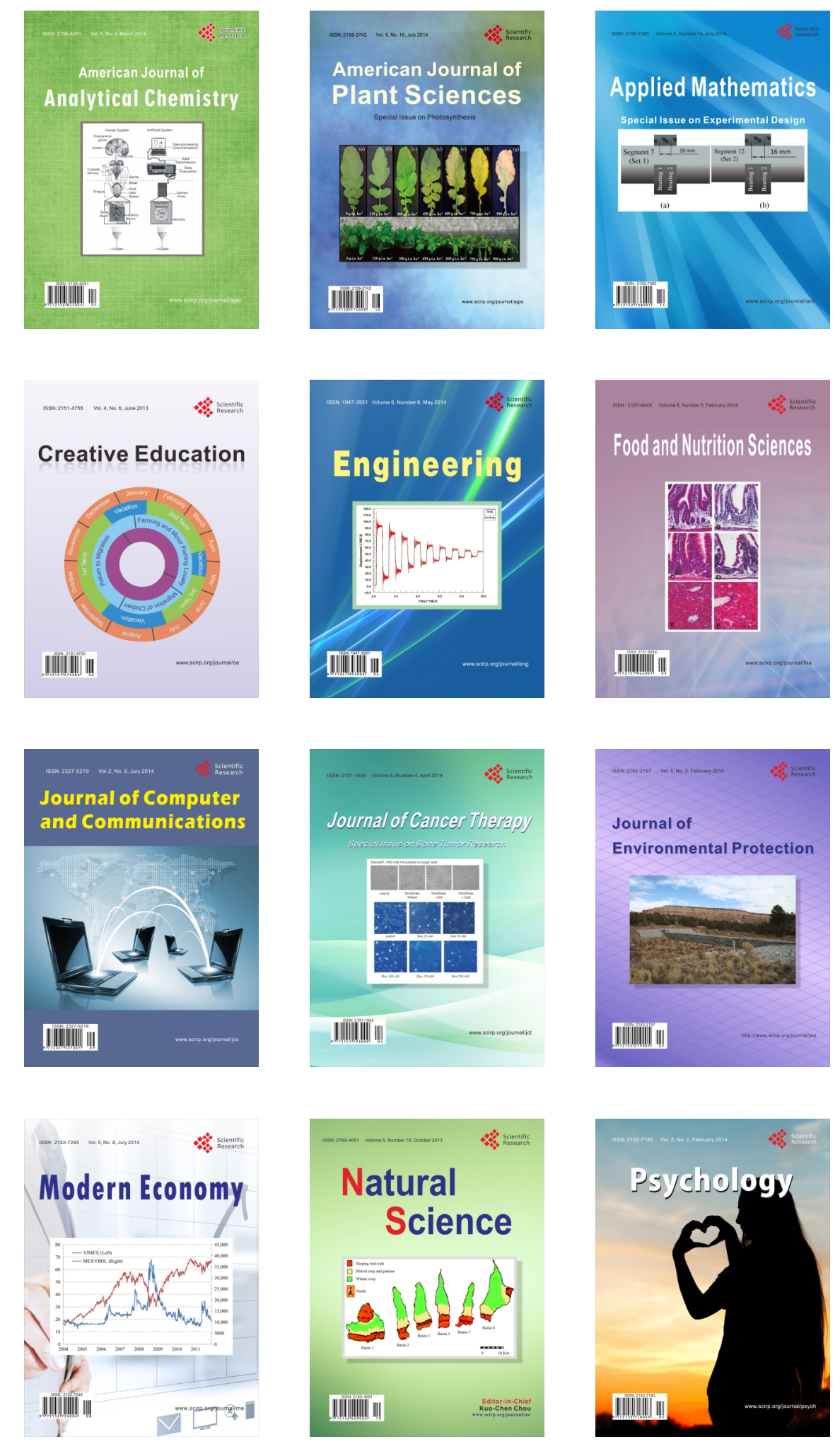